\title{
POSIÇÕES DE PROFESSORES EM FORMAÇÃO E PROFESSORES FORMADORES (ENTRE)VISTAS EM ATIVIDADES DIDÁTICAS ${ }^{1}$ : PROVOCAÇÕES SOBRE AUTORIA E LETRAMENTO ACADÊMICO
}

\author{
Emerson Tadeu Cotrim Assunção \\ Fernanda de Castro Modl
}

\begin{abstract}
RESUMO: O objetivo deste artigo é discutir sobre questões vinculadas ao letramento acadêmico (BARTON; HAMILTON, 2000; LEA; STREET 1998), a partir da tematização de aspectos relativos à construção da autoria (MATENCIO, 2002, 2006) em gêneros acadêmicos. A discussão é orientada pela análise de posições de professores em formação (licenciandos em Letras) em dialogia com dois de seus professores formadores materializadas em respostas a duas atividades didáticas que integram a agenda de trabalho de uma disciplina. Assumindo uma perspectiva discursiva (MONDADA; DUBOIS, 2003; POSSENTI, 2004) e metodologicamente amparados em princípios da pesquisa qualitativa (FLICK, 2002; MINAYO, 2012), dedicamo-nos a demonstrar a importância de que a atividade docente universitária leve em consideração representações sociais dos interlocutores que estão a orientar e, assim, a explicar o agir na universidade. Aqui, essas representações vinculam-se sobretudo ao trabalho em grupo, à produção de texto e à construção da autoria.
\end{abstract}

PALAVRAS-CHAVE: Autoria; Gêneros discursivos acadêmicos; Letramento acadêmico; Representações sociais; Sala de aula universitária de Letras.

\section{Introdução}

\footnotetext{
${ }^{1}$ As posições, aqui apresentadas como objeto de exame, advém de um corpus maior constituído no âmbito de uma pesquisa de mestrado (ASSUNÇÃO, 2016).

* Mestre em Letras: Cultura, Educação e Linguagens (PPGCEL) pela UESB. Professor auxiliar da Universidade do Estado da Bahia (UNEB). Integra o GELAT (Grupo de Estudos em Linguística Aplicada e Transdisciplinaridade) CNPQ-UNEB.

** Doutora em Linguística e Língua Portuguesa pela PUCMINAS. Professora titular da Universidade Estadual do Sudoeste da Bahia (UESB), onde atua no Departamento de Estudos Linguísticos e Literários (DELL), na Área de Metodologia e Prática de Ensino (AMPE), e no Programa de Pós-graduação em Letras: Cultura, Educação e Linguagens (PPGCEL) na linha de pesquisa Linguagem e Educação. Integra o GPLED (Grupo de Pesquisa em Linguagem e Educação) CNPQ - UESB.
} 
Como professores formadores em cursos de licenciatura em Letras, temos sempre buscado promover reflexões sobre a natureza e, portanto, as especificidades do trabalho do professor. Subjacente a essa preocupação está o alinhamento aos princípios de que há complexidade nas condutas de professores em situação de trabalho (LACOSTE, 1995) e ainda que as tarefas interacionais de professor e alunos são sempre complementares (MATENCIO, 2001) e institucionais.

Por isso, acreditamos que toda pesquisa em Linguística Aplicada, que elege a sala de aula como campo de pesquisa e/ou professores e alunos como sujeitos de pesquisa, soma a um exercício que concorre para a desobvilização do trabalho educacional.

Modl e Biavati (2016) e Ribeiro e Modl (2015) têm apontado para a potencialidade de se considerar a interrelação entre representações sociais e o agir profissional no exercício da docência universitária na formação inicial do professor. As autoras sinalizam como têm sido surpreendidas em salas de aula de graduações em Letras pela "força e lugar de representações sociais (MOSCOVICI, 1989) diversas advindas do discurso do senso comum acerca de um vasto conjunto de referentes que permeiam o trabalho interacional do professor" (MODL; BIAVATI, 2016, p. 100).

Tudo isso encontra eco na reflexão que este texto registra, afinal, interessa-nos aqui, analisar aspectos entrevistos nas ações dos pares interacionais aluno e professor em situações reais de trabalho ${ }^{2}$ que visam descortinar nuances que informam sobre performances de uso da língua(gem) e, assim, colocam em evidência um (não)“saber fazer” e um (não)“saber dizer" relativos ao universo de produção de práticas linguageiras características da Universidade (MATENCIO, 2003), por meio das quais professores em formação aprendem não apenas gêneros acadêmicos, mas também (re)constroem posições teórico-metodológicas sobre termos caros à sua área de saber e de atuação profissional. O que certamente

\footnotetext{
2 Os dados advêm de interações didáticas, ocorridas no semestre 2015.2, entre uma turma do V semestre de uma licenciatura em Letras de uma Universidade estadual do interior da Bahia e dois de seus professores, um da disciplina Seminário Interdisciplinar de Pesquisa - (doravante SIP), que tem como especificidade ser contínua, ou seja, é uma aposta curricular que vai do primeiro ao sétimo semestre e traz gêneros acadêmicos escritos e orais diferentes em cada semestre - e outro docente do semestre, orientador do grupo.
} 
ocorre, por meio de desestabilizações de representações sociais, compreendidas como "uma forma de conhecimento, socialmente elaborado e compartilhado, que tem um objetivo prático e concorre para a construção de uma realidade comum a um conjunto social” (JODELET, 1989, p. 36).

Representações sociais essas advindas do senso comum e até mesmo de experiências dos licenciandos vivenciadas como alunos da educação básica, por exemplo, relativas ao que seja texto, língua(gem), trabalho em grupo, fazer pesquisa, autoria e docência nos são, aqui, caras. Tais representações, que sustentam necessariamente compreensões sobre um vasto território conceitual, se distanciam do olhar profissional a ser (re)construído para focalizar esses referentes/conceitos nas disciplinas da licenciatura.

E é exatamente nesse ponto que destacamos o trabalho com a noção de representação social, saber que existem posições/interpretações/compreensões cristalizadas concorrentes a aquilo que está sendo tematizado pelo professor formador na sala de aula universitária incita a mobilização explícita desses pré-construídos (PASSOS; MODL, 2015). "Nessa mobilização, o professor-formador terá condição de promover ressignificações, (trans)formações e, nesse cenário, poder-se-á obter uma nova ordenação, uma recategorização, a partir de novas ancoragens” (RIBEIRO; MODL, 2015).

O que estamos com isso dizendo é que ao voltarmos o nosso olhar para práticas no âmbito da universidade, precisamos compreender as interações que se descortinam entre professor formador (professor universitário) e professor em formação (licenciando), assim como entre dois licenciandos (professores em formação) e dois professores formadores como relações profissional-formativas que requerem/levam a reconstrução de saberes e habilidades com vistas ao exercício profissional, seja ele imediato ou futuro. Tais relações são performatizadas, também, por meio de ancoragens em representações sociais.

Como alerta Matencio (2009), centrando-se nas especificidades dos licenciandos em Letras, "os processos formativos envolvendo a língua(gem) escrita ou falada devem, em quatro anos, levar a grandes alterações em termos de saberes”.(MATENCIO, 2009, p. 19). Saberes esses, acrescentamos, sempre vinculados a representações sociais. 
Isso posto, esclarecemos que o presente artigo analisa três diferentes situações de interlocução, que informam sobre práticas docentes na universidade e, ao mesmo tempo, sobre representações sociais que orientam tais práticas.

Duas dessas interlocuções analisadas ancoram-se no par interacional professor formador e professores em formação, no interior de aulas e, portanto, se materializam-se em pergunta e respostas a atividades didáticas (sendo uma escrita e outra oral promovida pela orientação em grupo para correção de uma versão de um texto escrito coletivamente). Por fim, analisamos turnos de fala advindos de uma conversa entre dois professores formadores (registrada em entrevista e, portanto, submetida também aos papéis comunicativos entrevistador e entrevistado e pesquisador e colaborador de pesquisa).

A nossa escolha por esse corpus informa sobre a nossa opção por analisar como diferentes posições circunstanciadas em usos diversos da linguagem na universidade pode informar sobre diferentes aspectos identitários de professores formadores e professores em formação na preparação para a profissionalização.

Orientando-nos por essas premissas, organizamos este texto em mais duas seções. No enquadre teórico-metodológico, i) sintetizamos informações sobre os dados, adiante analisados, momento em que esclarecemos sobre a pesquisa qualitativa, sinalizamos traços de pesquisa-ação, bem como apresentamos especificidades dos sujeitos da pesquisa e ii) indicamos a produtividade de discussões acerca de saberes que pautam as interações didáticas em sala de aula universitária para a compreensão do objeto de análise, quais sejam: representações de discentes aos processos de produções de atividades linguageiras acadêmicas; posições acerca do autor e da autoria em produções de gêneros acadêmicos e, por fim, os letramentos acadêmico e do professor em formação. Na seção seguinte, apresentamos dois exemplares de posições de professores e alunos em dois tipos de atividades didáticas (escrita e oral) e mobilizamos a categoria de análise escolhas lexicais (MONDADA; DUBOIS, 2003) para defesa de nossa posição. O texto é encerrado com provocações sobre autoria do texto coletivo e o letramento acadêmico, tendo em vista a agenda da formação inicial do professor. 


\section{Enquadre teórico-metodológico}

Os dados aqui trabalhados advém do banco de dados de Assunção (2016) e foram gerados em consonância com princípios da pesquisa qualitativa. Flick (2002) ensina-nos que [...] a pesquisa qualitativa dirige-se à análise de casos concretos em suas peculiaridades locais e temporais, partindo das expressões e atividades das pessoas em seus contextos locais. [...]. (FLICK, 2002, p. 37). Daí se afirmar que pesquisas dessa natureza evoquem questões que envolvem relações sociais circunstanciadas nas mais diversas esferas humanas, sendo a escola em sentido lato e a sala de aula em sentido stricto exemplos dessas esferas.

A sala de aula é por nós entendida como um microcosmo social (COELHO, 2011), já que agrupa sujeitos cujos comportamentos e representações refletem e refratam posições culturalmente observadas na sociedade maior que a escola integra. Por isso, uma abordagem de pesquisa que leve em consideração não apenas habilidades e técnicas, mas a "capacidade de se colocar no lugar do outro" (MINAYO, 2012, p. 623), desponta como uma forma mais sensível de compreender o que se predispõe a estudar.

A pesquisa, de que os dados originam, elegeu como campo de pesquisa, a sala de aula de uma turma de graduação em licenciatura em Letras de uma Universidade estadual baiana, local do exercício profissional do pesquisador. Os dados foram gerados e coletados, ao longo de um semestre letivo, o que possibilitou enxergar pontos que pareciam óbvios e já-conhecidos e também requereu considerar traços de uma pesquisa-ação. Ao pesquisar o seu ambiente de trabalho e a sala de aula onde exerce a função de docente, o docentepesquisador, além de deixar marcas de sua identidade, precisou refletir sobre a sua própria prática e, com isso, a pesquisa além de qualitativa figurou também uma pesquisa-ação (TRIPP, 2005) que tem como características centrais estratégias "para o desenvolvimento de professores e pesquisadores de modo que eles possam utilizar suas pesquisas para aprimorar seu ensino e, em decorrência, o aprendizado de seus alunos" (TRIPP, 2005, p. 445). 
A complexidade do dia a dia interacional de um grupo em uma disciplina culminou na constituição de um corpus multiforme ${ }^{3}$ que permitiu o tratamento de dados a partir do cotejamento de informações advindas de diferentes instrumentos da pesquisa, o que viabilizou diferentes movimentos de triangulação dos dados.

De igual modo, a triangulação de dados, "torna-se ainda mais produtiva se diversas abordagens teóricas forem utilizadas, ou ao menos consideradas, para a combinação de métodos [...].” (FLICK, 2002, p.32).

Para a leitura dos dados, elegemos a Análise do Discurso Francesa (ADF) como teoria de leitura (POSSENTI, 2004). Assim, quanto às categorias de análise, em decorrência da necessidade de encontrar recorrências e regularidades discursivas nos enunciados/posições dos sujeitos, escolhemos a categoria de análise escolhas lexicais (MONDADA; DUBOIS, 2003) para tratar as posições dos docentes e discentes acerca de questões que prefiguram as trocas didáticas entre professores e alunos.

Através da ADF, que aqui compreendemos como uma teoria de leitura (POSSENTI, 2004), aprendemos a enxergar um enunciado como a própria instância do que se diz e do que é dito, já que, em face de materialidades linguístico-discursivas em circulação, aquele que interpreta lança mão de dispositivos que permitam ler e desobvializar aquilo que aparece feito e rarefeito nas posições enunciadas.

\footnotetext{
${ }^{3}$ Para que se visualize o processo de geração e coleta de dados, esclarecemos a organização agenciada. Buscando indícios que dessem respostas ao objetivo geral da pesquisa, utilizamos três instrumentos de coleta de dados: i) Questionário Aberto: aplicado ao final da disciplina, constituído por 11 questões que buscaram respostas que permitissem (entre)ver argumentos em (des)favor das nossas apostas; ii) Entrevista com Docente-orientador do grupo, buscando nessa investida metodológica o ponto de encontro entre o reconhecimento de papéis desempenhados pelo docente no e para o tratamento do letramento acadêmico e na avaliação das práticas docentes e discentes em torno da construção dos gêneros acadêmicos oral e escrito e iii) Filmagem da sessão de orientação do Docente-orientador ao grupo, momento que procuramos indícios do letramento acadêmico em gestos formativos entre os envolvidos/participantes no/do processo de construção dos gêneros acadêmicos oral e escrito, bem como a sinalização de marcas de autoria.
} 
Como sujeitos da pesquisa ${ }^{4}$, contamos com 06 professores-formadores e 29 alunos do V semestre ${ }^{5}$, da graduação em Letras, do turno noturno: alunos que provêm das classes de trabalhadores, sendo 14 alunos em exercício profissional voltado para atividade da docência e 15 graduandos que exercem outras atividades que não têm relação com a graduação que cursam.

Esse dado pode apontar que, nos 04 (quatro) anos da graduação em Letras, esses alunos poderão se apropriar diferentemente de todo um conjunto de saberes voltados para a construção da identidade do professor de língua materna que integram os letramentos acadêmico e do professor ${ }^{6}$.

Neste artigo, esses sujeitos da pesquisa estão representados em uma amostragem menor de 6 discentes (que integraram o Grupo 3) e 1 docente-orientador. A escolha pelo Grupo 3 se deu por ser esse o grupo microcosmo da turma, apresentando todas as regularidades da classe, a saber: homem e mulheres, residentes na cidade e fora dela, professores em exercício e profissionais de outras áreas, casados e solteiros, com filhos e sem filhos, casal no grupo, evangélicos e não-evangélicos, características peculiares dos demais 5 gru$\operatorname{pos}^{7}$ da turma.

${ }^{4}$ Todos os sujeitos da pesquisa concordaram com a abordagem investigativa e nos autorizaram, por meio de documentos submetidos ao CEP-UESB, que as filmagens acontecessem, assim como aceitaram participar com a mostra de posições registradas nos demais instrumentos da pesquisa. Todos os nomes, cumpre lembrar, são fictícios.

${ }^{5}$ A escolha pelo V semestre se deu em decorrência de ser, no semestre 2015.2 (final de 2015 e início de 2016), o locus de trabalho do pesquisador (e autor do artigo) e, ao mesmo tempo, objeto do estudo desenvolvido no mestrado acadêmico do Programa de Pós-Graduação em Letras: Cultura, Educação e Linguagens (PPGCEL), da Universidade Estadual do Sudoeste da Bahia (UESB), realizado sob a orientação da coautora deste artigo.

${ }^{6}$ Cabe, aqui, trazer a voz de Kleiman (2006) quando toma o letramento do professor como ação de (re)configuração de identidade docente. Como este texto aborda, sobretudo, o letramento acadêmico, a Dissertação ASSUNÇã̃O (2016), de que este artigo é resultado, discursiviza, também, o letramento do professor em formação. Nesse sentido, como nos ensina Kleiman (2006) “Aprender a ler e escrever é um processo de construção identitária para os alunos de grupos dominados, mais pobres, de tradição oral, porque envolve a aprendizagem de práticas sociais de outros grupos que são, em sua maioria, alheios aos seus interesses, modos de ação e modos de falar. Daí a relevância de focalizarem-se os aspectos políticos do trabalho do professor que o conceito de mediador apaga e o conceito de agente de letramento ressalta". (KLEIMAN, 2006, p. 422)

${ }^{7}$ Os discentes se dividiram por afinidades: grupo de adventistas do $7^{\circ}$ dia, grupo de discentes que residem fora da cidade-sede da Universidade e grupo formado desde o primeiro semestre. Dos 6 grupos, há homens em 5 
Assumimos que as práticas de usos da linguagem na Universidade se pautam, sobretudo, na confluência e dialogicidade dos sujeitos afetados pelas práticas sociais ${ }^{8}$. Nesse processo de construção de identidade mediadas pelo uso linguageiro, os sujeitos agem e reagem em conformidade com aspectos socioistóricos que caracterizam e mesmo moldam as trocam simbólicas dos agentes envolvidos nos usos da linguagem: professores, alunos, currículo e sociedade. Esses aspectos socioistóricos, por sua vez, refratam representações sociais, isso porque "compartilhar uma ideia, uma linguagem, é também afirmar um laço social e uma identidade" (JODELET, 1989, p. 51).

O que se compartilha na universidade, ou seja, o que se vivencia nesse espaço de profissionalização ocorre por usos situados da língua(gem) enquadrados por produções de gêneros textuais constitutivos dos contextos acadêmicos de/para a formação profissional que se articulam a uma intricada rede de saberes tecida a partir da circulação e publicização de conhecimentos e resultados de pesquisas. A ponto, portanto, de afirmarmos que toda atividade de ensino pressupõe pesquisa e que pesquisas alimentam necessidade de didatização (ZANDWAIS, 2012).

Assim, saberes advindos de interlocuções proviententes da feitura e tematização coletiva da refacção/retextualização ${ }^{9}$ de gêneros acadêmicos permite o (re)conhecimento

agrupamentos, casal em 2 grupos, discentes com e sem filhos em todos os grupos e professores em exercício e outros profissionais em todos.

${ }^{8}$ Essa posição, de algum modo, remonta a uma distinção clássica em modos de se pensar o termo letramento, a partir da ideia de modelos autônomo e ideológico, como as posições defendidas por Street (2003, 2001, 1995), em que o letramento autônomo entende que há práticas neutras e universais, mas na verdade "mascara e silencia as questões culturais e ideológicas que a elas são subjacentes" (STREET, 2001, p. 07), e, em sentido oposto, o modelo ideológico, que se efetiva por práticas sociais em que identidades e culturas dos sujeitos se deixam entrever refletindo e refratando questões de poder numa sociedade. É sobre o modelo ideológico que recai nossas investidas teóricas nesse artigo e nas posições por nós adotadas.

9 "Retextualizar, por sua vez, envolve a produção de um novo texto a partir de um ou mais textos-base, o que significa que o sujeito trabalha sobre as estratégias linguísticas, textuais e discursivas identificadas no texto-base para, então, projetá-las tendo em vista uma nova situação de interação, portanto um novo enquadre e um novo quadro de referência". (MATENCIO, 2003, p. 03-04) 
de lacunas nos processos de apropriação de saberes (MATENCIO, 2003), conforme mostraremos adiante na seção de análise. O que isto quer dizer é que, cabe à Universidade a promoção de aulas, tomando essas como espaços genuínos de socialização em que habilidades de uso da língua sejam diagnosticadas e aprimoradas a partir do enquadre da arquitetura dos gêneros acadêmicos, compreendendo essa arquitetura como uma necessidade de se conceber o "gênero como fenômeno sócio-cognitivo e o texto, ao mesmo tempo, como a materialidade do processo que se constrói na atividade e produto dessa atividade" (MATENCIO, 2003, p. 02).

Para discutirmos sobre a apropriação de saberes profissionais e também sobre reconfiguração de representações sociais, atentamo-nos para o agenciamento de discursos, a negociação de sentidos e a construção da autoria, aspectos arrolados como basilares por Matencio (2003) em suas pesquisas sobre letramento acadêmico.

Se os estudos anteriores não apontavam para a sala de aula universitária como eficiente ou ineficiente no tocante à produção de gêneros acadêmicos pelos discentes da graduação, hoje, ganha destaque estudos que permitem ver nessa mudança uma justificativa de alteração de interesses de pesquisa ou de efeitos da democratização do ensino superior para grupos sociais menos favorecidos egressos de um ensino médio deficitário.

Entram no curso de licenciatura em Letras sujeitos advindos de grupos sociais diversos que, como é o caso da pesquisa que aqui se publiciza ${ }^{10}$, trazem deficiências de uma educação básica ineficiente, em termos de agenciamento da escrita e de práticas envolvendo

\footnotetext{
${ }^{10}$ Entram nas universidades discentes que "provêm de famílias que enfatizam pelo menos a importância simbólica de ler e escrever, daí seu sucesso na escola e na obtenção de um grau profissional. Ao fazer isso, eles escapam à norma. Embora concordemos com resultados de pesquisa que indicam que o letramento começa na família e que há diferenças significativas nos modos de usar a linguagem entre famílias de classe trabalhadora e famílias dos grupos majoritários (Heath, 1983), acreditamos ser mais relevante, para a transformação e a mudança, aprender como um caminho singular, individual de sucesso é conseguido, num processo que geralmente representa fracasso para um grupo social (cf. Ribeiro, 2005), em vez de pôr as práticas de letramento de sujeitos mais familiarizados com práticas de leitura de prestígio como o parâmetro ou norma de comparação. Em outras palavras, interessanos descobrir, nos seus relatos, como os alfabetizadores subvertem, para usar as palavras de Certeau (1994), a ordem social, fazendo-a colaborar para atingir seus próprios propósitos". (KLEIMAN, 2006, p. 414).
} 
gêneros textuais/discursivos orais e escritos, e que não fazem o curso por aptidão, mas, muitas vezes, como uma possibilidade de conclusão de um ensino superior.

Lea e Street (1998) compreendem letramento acadêmico em sentido lato, visto que o tomam como "[...]práticas sociais de leitura e escrita matizadas e situadas, as quais abrangem do ensino fundamental ao universitário e ao pós-graduado (LEA; STREET, 1998, p. 368-369). Na universidade, encontramos um locus de reflexão sobre o contexto de emergência do graduando e as suas construções identitárias e de engajamento linguageiro que subjazem um renque de pré-construídos advindo de toda uma história de vida e de usos da linguagem em processos de escolarização.

Nesse sentido, levando em consideração todo o trajeto educacional do sujeito, o que o letramento acadêmico materializa é o jogo performativo de uso da língua(gem) entre um "saber fazer" e um "saber dizer" relativos ao letramento acadêmico como ato de inserção do aluno no "universo de produção" (MATENCIO, 2003, p. 05) de práticas características da universidade e de um dado curso de graduação. Ou seja, "a relação entre "saber fazer" e "saber dizer" envolve, naturalmente, a compreensão da especificidade do discurso científico e de sua articulação com os discursos de transmissão de conhecimentos" (MATENCIO, 2003, p. 05).

Por essa razão, o uso da linguagem nas salas de aula universitária ou nas atividades nela demandadas é por nós entendido como processo de emancipação do sujeito com vistas à sua profissionalização. Matencio (2003) aposta que, através da produção de textos pelos acadêmicos, notadamente quando há uma interlocução mais interventiva entre docentes e discentes envolvidos no processo de facção e refacção textual, os textos acadêmicos partem da arena de conflitos e chegam ao palco de acordos.

Em síntese, é preciso apostar na sensibilidade para um fazer pedagógico curricular que considere, portanto, a trajetória de vida do sujeito que, quer por política de expansão do ensino superior, quer por coragem de enfrentar um sistema totalmente meritocrático de acesso à academia, chegou e chega à universidade. Assim, temos que 
a opção pelo modelo do letramento acadêmico como a forma mais adequada de compreender como os alunos revelam e constroem a condição letrada exigida pela universidade reflete uma preocupação muito grande com os discursos que circulam dentro dessa esfera, de que o aluno que ingressa na graduação é "iletrado", "não sabe ler nem escrever" ou "precisa ser alfabetizado na graduação". (OLIVEIRA, E; 2009, p. 09)

Vem daí a necessidade de pesquisas que tragam para a cena acadêmica a questão da produção textual cada vez mais significativa na universidade, vez que hoje, em muitos casos, conforme escritos de uma considerável produção crítica sobre letramento acadêmico, a produção científica de gêneros acadêmicos, pelos discentes, ainda é pouco relevante e não ocupa lugar de destaque nas aulas.

Quando o aluno chega à universidade entra em contato com novos gêneros textuais/discursivos que circulam na academia, os gêneros acadêmicos. Daí, então, escrever em um outro universo de práticas, marca, muitas vezes, um espaço de descobertas conflituoso. A escrita na e para a universidade pressupõe o conhecimento do gênero, a compreensão da demanda de produção, as questões envolvendo autoria, o agenciamento de discursos e vozes, a negociação de sentidos e a valorização, tanto pela instituição, quanto pelas práticas didáticas, da escrita como emancipação e construção de sentidos.

A aposta nos gêneros textuais/discursivos acadêmicos como mediação entre o "saber fazer" e o "saber dizer" evidencia a necessidade de compreender o que são gêneros e quais as demandas e finalidades desses nos contextos de publicização em espaços formais de ensino superior.

As definições de gêneros que encampamos na nossa escrita estão intimamente ligadas ao que nos ensina Bakhtin (2003). Para ele, só nos comunicamos, falamos e escrevemos, através de gêneros do discurso, sendo eles que orientam as nossas atividades de usos da linguagem. Desse modo, há um infindável repertório de gêneros e, muitas vezes, nem nos damos conta disso, vez que as possibilidades da comunicação humana são muito diversas. 
Os sujeitos ingressantes nas universidades vão processualmente construindo conhecimentos acerca da arquitetura dos gêneros acadêmicos e, muitas vezes, demoram a compreender suas finalidades e, assim, o que, de fato, está em jogo quanto à construção dos saberes, daí ser comum "bricolagem" de enunciados e vozes de outros sem a demarcação explícita de sua voz no texto que produz. Assim, é preciso defender uma "construção de saberes sobre como agir nas práticas discursivas em que se configuram os gêneros; apropriação de conceitos acadêmico-científicos; seleção de estratégias textual-discursivas que contribuem para a construção de um projeto de dizer". (OLIVEIRA, A; 2012, p. 312).

É interessante ressaltar que, participar efetivamente do mundo da escrita acadêmica, implica reconhecer que, nas dadas condições de ensino hoje, “[...]o aluno é aprendiz de uma escrita, e não tem um lugar legítimo, de autoridade, na maioria dos gêneros que produz” (MARINHO, 2010, p. 368), pois, muitas vezes, os textos produtos dos sujeitos na graduação são precários nos gerenciamentos de vozes e discursos, fazendo com que a materialidade linguístico-discursiva do texto acadêmico não apresente a voz de quem escreve, deixando (entre)ver uma arena discursiva de teorias lidas sem, contudo, o posicionamento subjetivo de quem textualiza.

Como o processo de escrita, mesmo a escrita acadêmica, é carregado de certos préconstruídos, é preciso apostar em mecanismos que evidenciem a configuração textual no (per)curso da escrita, quais sejam:

i) "o gerenciamento de vozes", uma vez que as dificuldades dos graduandos sobre o tratamento dos mecanismos enunciativos aponta para a dificuldade dos alunos perceberem "os traços que distinguem os modos de organização e funcionamento dos discursos científicos e de divulgação daquele que se tem no discurso didático, que lhe é mais familiar"'(MATENCIO, 2003, p. 09);

ii) "a negociação de sentidos", ou seja, quando, nas interações sociais, "os sujeitos selecionam determinadas formas de conceber os objetos, fundamentados em sua experiência cultural e intercultural prévia, o que os leva a determinadas ações de linguagem[...]". (MATENCIO, 2009, p. 20) e, por fim, 
iii) "a construção da autoria" que, mediante atividades de reescrita textual aponta para um caminho promissor de construção de marcas identitárias do autor face ao que está sendo textualizado, já que, como apostamos aqui neste estudo, escrever se faz reescrevendo, em outras palavras, é necessário que as trocas didáticas efetivas entre docentes e discentes no processamento textual "favoreçam a emergência da autoria de seus alunos" (TFOUNI, 2013, p. 42).

Quando entendemos o gênero textual/discursivo acadêmico artigo científico como materialidade que permite (entre)ver o gerenciamento de voz, a negociação de sentidos e marcas de autoria, é necessário voltar nossos olhares não apenas para o “feito" textual, mas sim para o processo do "fazer". O texto final, no caso de nossa pesquisa o artigo científico, é uma materialidade que permite evidenciar os mecanismos de ação e reação entre docentes, discentes e coisas do mundo.

Compreender, entretanto, como os sujeitos se posicionam na emergência da escrita é o que nos dará mostras do seu letramento acadêmico, pois, olhar para o processo em vez de voltar o olhar apenas para o produto garante-nos capturar indícios de como os sujeitos escrevem, porque escrevem e qual o papel das universidades, do currículo e dos docentes na inserção dos sujeitos em práticas efetivas de uso linguageiro acadêmico.

Olhar para a sala de aula universitária como espaço controverso de posições-sujeito e lugar genuíno da dialogia professor-aluno em referenciação a objetos de ensino caros à profissionalização e para as (des)estabilizações dela provenientes no campo da escrita e do letramento acadêmico requer perceber como o "saber fazer" está diretamente ligado ao "saber dizer", vez que, “ a relação entre "saber fazer" e "saber dizer" envolve, naturalmente, a compreensão da especificidade do discurso científico e de sua articulação com os discursos de transmissão de conhecimentos” (MATENCIO, 2003, p. 05).

À guisa de conclusão, no processamento textual da esfera acadêmica é preciso

ter claro que movimentar-se textualmente e discursivamente entre um "saber fazer" próprio da atividade formativa a um "saber dizer" próprio da atividade acadêmica (duas instâncias que não se excluem, mas se complementam) implica distanciamentos e aproximações 
que não se dão de forma tranquila; diferentemente, caminhar entre esses saberes exige competências e habilidades que se corporificam na complexa rede de articulações entre eles, ou seja, que são demandadas, sempre, nas articulações que permitem aproximar-se de um gênero, para apropriar-se dele, e, ao mesmo tempo, distanciar-se, para que um saber não se sobreponha ao outro. (OLIVEIRA, A. 2012, p. 318)

Traçar esse movimento é significativo para sinalizar como o sujeito que se encontra nesse novo espaço de construção de conhecimento e se percebe em relação ao uso da linguagem e de seus processos de construção de identidade naquilo que escreve (BARTON, HAMILTON, 2000). Assumir que o texto produzido e em produção pelos alunos na universidade traz mostras do que a academia tem feito e do que ela poderá fazer para que os sujeitos escrevam atribuindo sentido ao que textualizam é um passo fundamental para acessar o processo de letramento acadêmico e, assim, de exercício da escrita nas práticas sociais de uso da linguagem.

\section{Análise dos dados}

Aqui, apresentamos 01 (um) exercício de triangulações com os dados advindos do corpus multiforme. As análises se prestam a rastrear indícios dos letramentos acadêmico e da autoria do texto produzido pelos discentes sob a orientação do Docente-orientador e do Professor do SIP V.

A fim de facilitar a visualização, colocamos lado a lado, a seguir, dados advindos de respostas a uma mesma tarefa didática escrita, por meio da qual um professor-formador suscita de cada licenciando (integrante do Grupo 3) uma posição individual acerca: i) da organização do trabalho de grupo (coluna da esquerda) e das próprias ações (coluna da direita). A comparação entre as posições dos diferentes integrantes do Grupo permite acessarmos a diferença nos modos como compreende(ra)m e, assim, significa(ra)m o trabalho em grupo.

Logo abaixo, das colunas da esquerda e da direita, apresentamos a troca didática entre o docente orientador e os licenciandos sob sua orientação. É curioso se atentar, no 
momento de leitura dessa parte do quadro, que todos os seis licenciandos (Arruda, Malvina, Enya, Edvalda, Luágina e Denise) estão presentes na interação face a face com o orientador.

\begin{tabular}{|l|}
\hline \multicolumn{2}{|c|}{ TRIANGULAÇãO: autor e aut } \\
\hline \multicolumn{2}{|c}{ Question } \\
\hline $\begin{array}{l}\text { Questão 06. A versão escrita do artigo que o } \\
\text { seu grupo apresentou, assim como a publiciza- } \\
\text { ção oral, são fruto de um trabalho coletivo. } \\
\text { Como o seu grupo se organizou para isso? }\end{array}$ \\
\hline $\begin{array}{l}\text { Arruda: A parte oral sim foi construída com a co- } \\
\text { laboração direta de todo o grupo, já a parte escrita } \\
\text { foi mais restrita a mim, mas contando com a ajuda, } \\
\text { textos e sugestões de todos os integrantes do } \\
\text { grupo. }\end{array}$ \\
\hline
\end{tabular}

Malvina: Não fez a tarefa

Enya: Cada um ficou responsável por uma pesquisa a respeito do tema, e assim, cada integrante do grupo teria que escrever um pequeno texto a respeito do que pesquisou, para depois seria socializado entre o grupo para a escrita do artigo.

Edvalda: Não fez a tarefa

Luágina: Sim, em parte, pois entregávamos os nossos escritos ao nosso colega e ele alterava como queria.
Questão 05. O que você tem a dizer sobre o seu lugar na produção do artigo em grupo? Como você se autoavalia? Faria algo diferente?

Arruda: Penso que durante a produção do artigo eu fiz o meu melhor, tendo idealizado o tema, a maior responsabilidade coube a mim e eu acredito que correspondi a ela, porem acho que poderia ter tentado me aproximar e dialogar mais abertamente com o orientador e também me preparado melhor para a apresentação.

Malvina: Não fez a tarefa

Enya: Eu acredito que tenha contribuído com algumas ideias e pesquisas necessárias, e que ajudaram bastante na hora da produção do artigo, não mudaria nada, pois foi uma experiência bem válida.

Edvalda: Não fez a tarefa

Luágina: Participei de forma efetiva do trabalho, procurando sempre fazer o que me foi pedido, me daria uma nota 8,00. Participaria mais e exporia um pouco mais as minha ideias, palpitaria mais, questionaria algumas ideias do orientador, mas ainda estou trabalhando esse meu lado que não deixa eu expor as minhas ideias.

Denise: Licença maternidade.

Denise: Licença maternidade.

\section{Sessão de Orientação}

Docente-orientador 03: mas pode falar então... vou repetir... eu acho que o seu texto já tem isso tá? Arruda: [temos mais texto]

Docente-orientador 03: é porque assim ou um espaço de construção OU de transmissão do saber porque... uma coisa é uma coisa... ((falando a respeito do texto produzido pelos integrantes)) construir saber seria uma coisa e transmitir saber seria outra.... por quê? porque um concebe o sujeito como ativo nesse processo e o outro concebe o sujeito como passivo... ... no sentido de só basta chegar ao conhecimento pronto e não você fazer o caminho de chegar até o conhecimento... eu não quero aprender a dar nó no sapato eu quero velcro... ... nunca tinha pensado... nessa analogia

Arruda: ah 
Docente-orientador 03: hum... então esse tipo de coisa que eu acho que você precisa prestar atenção... no seu texto... isso aparece e você precisa destacar então qual seria a concepção de humano que está atrelado à ideia de espaço de construção OU espaço de transmissão de saber... fiquei confuso porque eu achei que todos esses autores estavam falando da mesma escola até onde eu lembro... não conheço Cris tá?... achei que eles estavam falando da mesma... nem Macedo... achei que eles estavam falando da mesma conversa... me parece que você não leu nem esse nem esse nem esse nem esse ((apontando para o texto)) parece que você leu essa referência... todos esses autores num outro lugar

Arruda: eu li sobre eles

Docente-orientador 03: foi o que eu pensei

Arruda: eu li diretamente não... ah não [foi diretamente o::: $=$

Docente-orientador 03: [nessa citação específica

Arruda: nessa daí não

Docente-orientador 03: ah me parece... parece isso uma representatividade limitada já marquei isso toda vez no seu texto... eu não faço ideia do que seja isso

Arruda: a gente conversou com professor-pesquisador nessa semana passada e a gente tirou isso aí

Docente-orientador 03: no seu texto... mas isso aqui você já viu não é?

Arruda: hum-rum [eu já fiz as =

Docente-orientador 03: $\quad$ [que já faz uns dias que eu mandei

Arruda: as [correções] que você pediu INTEERRUP

Docente-orientador 03: então daí eu acho que de boa assi::m... né você pode vir direto para essa coisa aqui de... então concebe-se sujeito na perspectiva de::... pode falar então de características do sujeito aprendiz do sujeito aluno

Arruda: isso aí eu achei que eh... faltou no::... na conclusão dessa parte do texto

Docente-orientador 03: é... eu imaginei que a gente podia ir para esse lugar... tudo que está aí pode ficar não vejo problema a gente precisa definir para onde que a gente vai... então talvez a gente fosse... você pede a gravação para o professor-pesquisador... talvez a gente fosse pro:.: caminho... essa escola diz que sujeito é mais ou menos assim e por isso oferece tais formas de levar o conteúdo... portanto supondo produzi:r uma subjetividade que vai entender blá blá blá... e a O:Utra inclusive em função de uma abertura hum democrática no país... tem essa... a própria proposta já é diferente porque é uma participação política na educação [proposta]... [inclusive a gente] podia ir em outro lugar do texto e não nessa parte agora sabe? porque essa parte agora você só podia assim... você desdobrou falou o que era as duas escolas mais ou menos e vai falar do que a escola faz do sujeito assim... tal escola pensa... faz não... tal escola pensa assim e tal escola pensa assim outro e aí depois você já pode ir direto para considerar... então portanto

Arruda: ININT INTERRUP

Docente-orientador 03: tal escola ININT o sujeito passivo assim atendendo ao mercado blá blá blá e tal outra escola pretendia produzir um sujeito que respondesse a outras expectativas do tempo já que você gosta dessa ideia de falar que as duas escolas são produtos do tempo e são mesmo

Arruda: eu acho que.. não eu acho... eu acho::... você acha que é melhor a gente ir só por aí?

Docente-orientador 03: eu acho... do que misturar Bakhtin Vygotsky e essa gente toda

Arruda: ah é?

Docente-orientador 03: com certeza... dado o prazo

Arruda: não mas eu já tinha [estruturado] esse pessoal todo

Docente-orientador 03: ah então está ótimo... só que eu não vi isso aqui

Arruda: sim mas pois é eu falei para você... mas não foge disso aí eu acho que exatamente dentro do que a gente já fez que cabe... cabe não é até desnecessário colocar isso... desdobramento e tudo mais... não foge disso

\section{Quadro 01}

Triangulação: autor e autoria do gênero acadêmico 
Vertendo os nossos olhares para os dados, percebemos que: i) através do que dizem três membros do grupo, nos enunciados advindos da coluna da esquerda superior da tabela, referente ao questionário, há indícios linguístico-discursivos, percebidos nas modalizações pronominais (mim, a gente, (os) integrantes do grupo, nossos, ele) e verbais (ficou, pesquisou, entregávamos, alterava, queria), de que a construção dos gêneros acadêmicos foi relativamente coletiva e não integralmente coletiva, um modo, portanto, diverso do que se espera que decorra o trabalho em grupo. Já que há soberania mais precisa de um membro sobre os demais:

"A parte oral sim, foi construída com a colaboração direta de todo o grupo, já a parte escrita foi mais restrita a mim, mas contando com a ajuda, textos e sugestões de todos os integrantes do grupo". (Arruda, P6);

“ Cada um ficou responsável por uma pesquisa a respeito do tema, e assim, cada integrante do grupo teria que escrever um pequeno texto a respeito do que pesquisou, para depois seria socializado entre o grupo para a escrita do artigo". (Enya, P6) e

"Sim, em parte, pois entregávamos os nossos escritos ao nosso colega e ele alterava como queria". (Luágina, P6).

Nos dizeres de Arruda, há a indicação de que o gênero escrito artigo acadêmico foi mais de sua responsabilidade do que da do grupo, o que coaduna com o que diz Luágina, especialmente quando atribui a Arruda o poder de "alterar como quer" o que foi a ele apresentado.

Quando perguntamos, como o discente se autoavalia, (cf. na coluna da direita, parte superior da tabela referente ao Questionário), encontramos posições que indicam o protagonismo da escrita para a liderança do grupo de quem assume o papel de autor do texto. Se observarmos a resposta

\footnotetext{
"Penso que durante a produção do artigo eu fiz o meu melhor, tendo idealizado o tema, a maior responsabilidade coube a mim e eu acredito que correspondi a ela, porem acho que poderia ter tentado me aproximar e dialogar mais abertamente com o orientador e também me preparado melhor para a apresentação". (Arruda, P5)
} 
o discente assume a condição de autor, ao tempo que indicia que foi ele quem escolheu o tema da pesquisa.

Observando as modalizações linguísticas verbais (verbos no futuro do pretérito do indicativo - participaria, palpitaria, exporia, questionaria), utilizadas por Luágina, na resposta abaixo, que expressam um desejo de um fazer diferente, de agir mais pontualmente no e para o seu processo de revisão pessoal de posturas, com vistas ao seu letramento acadêmico, presentes nos enunciados:

"Participei de forma efetiva do trabalho, procurando sempre fazer o que me foi pedido, me daria uma nota $\mathbf{8 , 0 0}$. Participaria mais e exporia um pouco mais as minha ideias, palpitaria mais, questionaria algumas ideias do orientador, mas ainda estou trabalhando esse meu lado que não deixa eu expor as minhas ideias. (Luágina, P5)

percebemos que, mesmo após 5 semestres em curso, há ainda conflitos entre os papéis desempenhados pelos discentes em um curso de graduação, já que ainda há quem se sinta inseguro para dialogizar e dialetizar acerca dos objetos de ensino e de pesquisa. Além disso, é possível ler, nessas materialidades, fragilidades sobre a autoria dos exercícios linguageiros da discente “...fazer o que me foi pedido...” (Luágina, P5), que não evidencia o protagonismo da discente, e dificuldades com a assunção de posicionamento crítico de um aluno de graduação sobre tema/objetos de ensino, a que está exposto, como evidenciam as escolhas lexicais “...ainda estou trabalhando esse meu lado que não deixa eu expor as minhas ideias" (Luágina, P5). Quando falamos sobre letramentos acadêmico, percebemos fragilidades e dificuldades argumentativas como as que nos referimos nesse parágrafo, bem como lacunas nesses processos e necessidade de apostas em atividades de (re)tomadas linguageiras com objetivos de (re)configurações de identidade desses sujeitos.

E, por fim, quando observamos os enunciados "Eu acredito que tenha contribuído com algumas ideias e pesquisas necessárias, e que ajudaram bastante na hora da produção do artigo, não mudaria nada, pois foi uma experiência bem válida” (Enya, P5), percebemos, através das escolhas lexicais "algumas “ e “ajudaram”, o engajamento ainda relativo da discente no exercício da produção dos gêneros acadêmicos. 
Ainda nessa linha de análise, repetimos, aqui abaixo, as cenas transcritas para dar mostras de como as trocas didáticas entre o Orientador e o Grupo indiciam acerca da autoria e a liderança da produção acadêmica desses discentes.

245. Docente-orientador 03: mas pode falar então... vou repetir... eu acho que o seu texto já tem isso tá?

249. Docente-orientador 03: hum... então esse tipo de coisa que eu acho que você precisa prestar atenção... no seu texto.... isso aparece e você precisa destacar então qual seria a concepção de humano que está atrelado à ideia de espaço de construção $\mathrm{OU}$ espaço de transmissão de saber... fiquei confuso porque eu achei que todos esses autores estavam falando da mesma escola até onde eu lembro... não conheço Cris tá?... achei que eles estavam falando da mesma... nem Macedo... achei que eles estavam falando da mesma conversa... me parece que você não leu nem esse nem esse nem esse nem esse ((apontando para o texto)) parece que você leu essa referência... todos esses autores num outro lugar

250. Arruda: eu li sobre eles

251. Docente-orientador 03: foi o que eu pensei

252. Arruda: eu li diretamente não... ah não [foi diretamente o::: =

274. Docente-orientador 03: ah me parece... parece isso uma representatividade limitada já marquei isso toda vez no seu texto... eu não faço ideia do que seja isso

275. Arruda: a gente conversou com professor-pesquisador nessa semana passada e a gente tirou isso aí

276. Docente-orientador 03: no seu texto... mas isso aqui você já viu não é?

277. Arruda: hum-rum [eu já fiz as $=$

278. Docente-orientador 03: [que já faz uns dias que eu mandei

279. Arruda: as [correções] que você pediu INTEERRUP

280. Docente-orientador 03: então daí eu acho que de boa assi::m... né você pode vir direto para essa coisa aqui de... então concebe-se sujeito na perspectiva de::... pode falar então de características do sujeito aprendiz do sujeito aluno

281. Arruda: isso aí eu achei que eh... faltou no::... na conclusão dessa parte do texto

282. Docente-orientador 03: é... eu imaginei que a gente podia ir para esse lugar... tudo que está aí pode ficar não vejo problema a gente precisa definir para onde que a gente vai... então talvez a gente fosse... você pede a gravação para o professor-pesquisador... talvez a gente fosse pro::: caminho... essa escola diz que sujeito é mais ou menos assim e por isso oferece tais formas de levar o conteúdo... portanto supondo produzi:r uma subjetividade que vai entender blá blá blá... e a O:Utra inclusive em função de uma abertura hum democrática no país... tem essa... a própria proposta já é diferente porque é uma participação política na educação [proposta]... [inclusive a gente] podia ir em outro lugar do texto e não nessa parte agora sabe? porque essa parte agora você só podia assim... você desdobrou falou o que era as duas escolas mais ou menos e vai falar do que a escola faz do sujeito assim... tal escola pensa... faz não... tal escola pensa assim e tal escola pensa assim outro e aí depois você já pode ir direto para considerar... então portanto

283. Arruda: ININT INTERRUP

284. Docente-orientador 03: tal escola ININT o sujeito passivo assim atendendo ao mercado blá blá blá e tal outra escola pretendia produzir um sujeito que respondesse a outras expectativas do tempo já que você gosta dessa ideia de falar que as duas escolas são produtos do tempo e são mesmo

285. Arruda: eu acho que.. não eu acho... eu acho:.... você acha que é melhor a gente ir só por aí?

286. Docente-orientador 03: eu acho... do que misturar Bakhtin Vygotsky e essa gente toda

287. Arruda: ah é?

288. Docente-orientador 03: com certeza... dado o prazo

289. Arruda: não mas eu já tinha [estruturado] esse pessoal todo

290. Docente-orientador 03: ah então está ótimo... só que eu não vi isso aqui 
291. Arruda: sim mas pois é eu falei para você... mas não foge disso aí eu acho que exatamente dentro do que a gente já fez que cabe... cabe não é até desnecessário colocar isso... desdobramento e tudo mais... não foge disso

Observamos que dos 432 turnos de fala trocados entre os sujeitos da pesquisa nessa abordagem, apenas 43 turnos são dos demais membros do grupo que não Arruda e o Docente-orientador 03 . Ou seja, só esses trocam $90 \%$ dos turnos de fala que integram as trocas didáticas que marcam a orientação em torno da produção acadêmica do Grupo. Voltando nossos olhares para os turnos de fala, apenas para evidenciarmos o que estamos dizendo, o uso dos pronomes referenciais do discurso (negritados e sublinhados, evidenciam a liderança e quem é o autor dos gêneros), bem como mostram equívocos quanto ao que deveria ser o trabalho em grupo.

As instâncias de produção de um trabalho em grupo, como o SIP aposta e registra, precisam levar em consideração que o que sustenta essa atitude é a colaboração entre os sujeitos e o protagonismo de cada discente para e pelo grupo. As relações entre trabalho em grupo e autoria coletiva na/da produção linguageira deveriam ser inequívocas, já que se tratam de sujeitos em processos de construção de identidades de professores e que, em suas vivências de práticas didáticas, terão trabalhos como esse em seus cotidianos escolares.

Como a pesquisa ocorreu ao longo de um semestre letivo, à medida que coletávamos dados, já fazíamos uma leitura e análise para traçar o próximo movimento de investigação. Então, já havíamos percebido que Arruda, além de liderança, era o autor dos gêneros acadêmicos apresentados pelo grupo. Por isso, como registra os turnos retirados da última parte do quadro, que traz dados da entrevista realizada com o Docente-orientador, tematizamos a questão da autoria para saber o que tinha a falar sobre esse aspecto. Docenteorientador também atribui a Arruda a autoria do texto. Fizemos a pergunta que aparece transcrita abaixo e obtivemos a afirmativa:

43. Professor-pesquisador: [é só o Arruda...] você acha que é só ele que escreve mais?

44. Docente-orientador 03: não... é só ele que faz aquele texto 
Como a pergunta se utiliza do verbo "achar", que autoriza, entre outras coisas, uma provável incerteza, a resposta do entrevistado, pelo contrário, se inicia com uma negativa ao "acha" e termina com uma assertiva que mostra posicionamento firme do orientador. Como uma das características da produção acadêmica (MATENCIO, 2009) é a autoria, vemos que o grupo apresenta fraquezas nesse aspecto, vez que há um sujeito que assume essa posição e os demais parecem ir à reboque dele.

Essa triangulação trouxe informações muito preciosas para compreendermos como tomadas e retomadas de posições em auto e alter avaliações contribuem para discussões acerca de processos de letramentos. Como a construção da autoria indica processos de apropriação da linguagem acadêmica e de saberes conceituais e metodológicos caros a professores em formação (letramentos acadêmico e do professor) e por sermos, autor e coautora, professores da graduação em Letras de Universidades distintas, os dados aqui apresentados na análise contribuem para que continuemos atentos para nossos projetos didáticos de exercícios da docência, bem como nos sinalizam que a universidade pode fazer mais pelos cursos de licenciatura e pelos alunos que serão legitimados professores de língua materna.

\section{Considerações Finais}

Ao retomarmos as provocações que fizemos no título deste artigo, que tematiza noções de representação, autoria e letramento acadêmico de licenciandos em Letras em dialogia com professores-formadores no desenvolvimento da produção linguageira acadêmica (artigo científico), chegamos a algumas conclusões:

a) o fato de os gêneros acadêmicos (artigo e seminário) em construção no/do semestre não terem sido, de fato, coletivos afeta os modos de configuração do letramento acadêmico desses sujeitos, já que os discentes apresentaram fragilidades no e para o protagonismo na/da construção da autoria nos gêneros produzidos, uma vez que apenas Arruda assume a condição de autor e é pelo grupo pronunciado e legitimado como tal; 
b) os discentes do grupo trazem representações sobre o que é ser estudante de um curso de formação de professores ainda distantes de posições esperadas para discentes que já cursaram mais da metade da graduação (V semestre). $\mathrm{O}$ fato de serem alunos do noturno (já que trabalham durante o dia e quase não têm tempo para as atividades de estudo), e mais da metade não desenvolverem atividades laborativas de docência, impactam em seus processos de (re)configurações de identidades do que é ser professor;

c) a Universidade pode (e deve!) fazer mais pela inserção desses discentes em eventos situados de letramento, contribuindo para a emancipação do sujeito pelo viés da produção de gêneros acadêmicos com mais autonomia e protagonismo, impactando em seus modos de (re)configurações de identidades de licenciandos em Letras e futuros docentes de língua materna.

Em síntese, tudo isso sinaliza para o modo como os sujeitos agem e reagem pela linguagem aos objetos de ensino e de aprendizagem que perfazem o trabalho com a produção de gêneros acadêmicos em produção, que, consequentemente, registram as alterações no modo como professores em formação compreendem a língua(gem), o texto e a autoria.

Dados avindos de situações reais de docência, portanto, quando transcritos e analisados, auxiliam-nos a compreender facetas da prática docente como a busca por uma distribuição da atenção e da palavra cada vez mais igualitária (MODL, 2015; ASSUNÇÃO; MODL, 2015) na interação didática e até mesmo o uso da palavra para ações de reprimendas (MATENCIO, 2001) de comportamentos discentes e tematização de representações sociais distanciadas entre o que se faz/diz e o que se deveria dizer e fazer, com vistas a esclarecer sobre efeitos e defeitos provenientes da troca didática e entre pares em sala de aula. Isso porque há a

necessidade de que atribuamos um estatuto outro para aquilo que professor e alunos dizem, não dizem, fazem e não fazem no espaço discursivo da sala de aula. Abstração essa que, como analistas, nos auxilia a desobvializar o que fazemos e deixamos de fazer enquanto investidos nas posições-sujeito aluno e professor. (ASSUNÇÃO; MODL, 2015, p. 556-557). 
Afinal, o trabalho do profissional professor não é algo transparente, sendo atravessado pela complexidade das ideologias dos grupos dos quais participamos e das interpretações estabilizadas historicamente que orientam e explicam o modo como agimos e reagimos no mundo (ASSUNÇÃO; MODL, 2015).

\begin{abstract}
:
The aim of this paper is to discuss issues about academic literacy (BARTON; HAMILTON, 2000; LEA; STREET 1998), from a thematization of authorship construction aspects (MATENCIO, 2002, 2006) in academic genres. The discussion is guided by position analysis of pre-service teachers (graduating in Letters) in a dialogism with two trainer teachers, materialized in responses to two didactic activities that integrate the work agenda of a discipline. The paper takes a discursive perspective (MONDADA; DUBOIS, 2003; POSSENTI, 2004; ORLANDI, 2013) and it is methodologically based on principles of qualitative research (FLICK, 2002; MINAYO, 2012), we intend to demonstrate the importance of university teaching activity considers social representations of the interlocutors who are guiding and thus explaining how to act in university. Here, these representations are mainly related to group work, to text production and authorship construction.
\end{abstract}

KEYWORDS: Academics discursive genres; Academic literacy; Authorship; Letters University classroom; Social representations.

\title{
REFERÊNCIAS
}

ASSUNÇÃO, Emerson Tadeu Cotrim. MODL, Fernanda de Castro. Sala de aula como espaço controverso de posições-sujeito: o dizer, o não dizer, o silêncio e as relações de poder em uma aula sobre o "dia da consciência negra”. Revista Fólio, v.7, número 2, p. 555-579, 2015.

ASSUNÇÃO, Emerson Tadeu Cotrim. Os letramentos acadêmico e do professor e(m) gestos formativos: a disciplina Seminário Interdisciplinar de Pesquisa (SIP) como locus de investigação. 2016. 260 p. Dissertação. (Mestrado em Letras) - Universidade Estadual do Sudoeste da Bahia, Vitória da Conquista, 2016.

BAKHTIN, M. Estética da criação verbal. São Paulo: Martins Fontes, 2003.

BARTON, D.; HAMILTON, M.; IVANIC, R. Situated Literacies: reading and writing in context. New York: Routledge, 2000.

FLICK, U. Introdução à pesquisa qualitativa. Porto Alegre: Artmed, 2002. 
KLEIMAN, A.R.B. Professores e agentes de letramento: identidade e posicionamento social. Revista Filol. linguist. port., n. 8, p. 409-424, 2006. Disponível em: < http:/ /www.revistas.usp.br/flp/article/view/59763/62872> Acesso em: 01 jul. 2015

KLEIMAN, A. R. B.; MATENCIO, Maria de L. M (Org.) Letramento e formação de professores: práticas discursivas, representações e construção do saber. Campinas, SP: Mercado de Letras, 2003.

Os significados do letramento: uma nova perspectiva sobre a prática social da escrita. Campinas, SP: Mercado das Letras, 2002.

JODELET, Denise. Representations sociales: un domaine en expansion. In: JODELET, D. (Org.). Les Représentations Sociales. Paris: Press Universitaires de France, 1989.

LEA, M.R.; STREET, Brian. Student Writing in higher education: an academic literacies approach. Studies in Higher Education. London, v. 23, n. 2, p. 157-16, June, 1998.

MAINGUENEAU, D. Novas tendências em análise do discurso. Campinas: Pontes, 1989.

MARINHO, M. A escrita nas práticas de letramento acadêmico. Revista Brasileira de Linguistica Aplicada (RBLA), Belo Horizonte, v. 10, n. 2, p. 363-386, 2010. Disponível em: <http://www.scielo.br/pdf/rbla/v10n2/05.pdf > Acesso em: 05 jun. 2015.

MATENCIO, M. de L. M. Estudos do letramento e formação de professores: retomadas, deslocamentos e impactos. Revista Calidoscópio, Vol. 7, n. 1, p. 5-10, jan/abr 2009. Disponível em: < http://revistas.unisinos.br/index.php/calidoscopio/article/view/4850> Acesso em: 05 jun. 2015.

Gêneros na formação do professor: construção de saberes e representações em atividades interacionais. Estudos Linguisticos/Linguistic Studies, 3, Edições Colibri/CLUNL, Lisboa, 2009, p. 17-28.

Referenciação e retextualização de textos acadêmicos: um estudo do resumo e da resenha. In: III CONGRESSO INTERNACIONAL DA ABRALIN, Rio de Janeiro. Anais. UFRJ, 2003. p.210-232.

- Estudo da língua falada e aula de língua materna: uma abordagem processual da interação professor/alunos. Campinas: Mercado de Letras, 2001. 
MINAYO, M.C.S. Análise qualitativa: teoria, passos e fidedignidade. Ciência \& Saúde Coletiva, 17 n. 3, p. 621-626, 2012. Disponível em: <http://revistaseletronicas.pucrs.br/ojs/index.php/faenfi/index > Acesso em: 30 out. 2015.

MODL, Fernanda de Castro. Interação didática: apontamentos (inter)culturais sobre o uso da palavra e a formação do sujeito aluno. Revista SCRIPT $A$, Belo Horizonte, $2^{\circ}$ semestre de 2015, p.117-149.

MODL, Fernanda de Castro; RIBEIRO, Pollyanne Bicalho. (Re)Construção Identitária em movimentos de referenciação: representações sociais sobre o professor na formação inicial. Nonada, Porto Alegre, n. 24, p. 61-82, 1. sem. 2015.

MODL, Fernanda de Castro; BIAVATI, Nádia Dolores Fernandes. Cultura escolar e desnaturalização do olhar: a vinheta narrativa e(m) suas contribuições para um contraponto intercultural. Revista Fólio, v.8, número 2, p. 99-125, 2016.

MONDADA, L.; DUBOIS, D. Construção dos objetos de discurso e categorização: uma abordagem dos processos de referenciação. In: CAVALCANTE, M. M.; RODRIGUES, B. B.; CIULLA, A. Referenciação. São Paulo: Contexto, 2003, p. 17-52.

MOSCOVICI, Serge. Representações Sociais: investigações em psicologia social. Tradução de Pedrinho A. Guareschi. Petrópolis: Vozes, 1989.

OLIVEIRA, A. R. de. Do relato de experiência ao artigo científico: questões sobre gênero, representações e letramento na formação de professores a distância. SCRIPTA, Belo Horizonte, v. 16, n. 30, p. 307-320, $1^{\text {o }}$ sem. 2012.

OLIVEIRA, E. F. Letramento acadêmico: principais abordagens sobre a escrita dos alunos no ensino superior. 2009. Disponível em: < http://www.ichs.ufop.br/memo$\mathrm{rial} / \mathrm{trab2} / 1113 . \mathrm{pdf}>$ Acesso em 23 jul. 2015.

PASSOS, Jamille Santos; Modl, Fernanda de Castro. A Linguística Aplicada como objeto de discurso: implicações para formação inicial do professor de língua inglesa. Revista Fólio, v.7, número 2, p. 707-733, 2015.

POSSENTI, S. Teoria do discurso: um caso de múltiplas rupturas. Introdução à linguística: fundamentos epistemológicos, v. 3, p. 353-392, 2004.

STREET, B. Letramento sociais: abordagens críticas do letramento no desenvolvimento, na etnografia e na educação. São Paulo: Parábola, 2014. 
. Eventos de letramento e práticas de letramento. In.: MAGALHÃES, I. (Org.). Discursos e práticas de letramento: pesquisa etnográfica e formação de professores. Campinas, SP: Mercado das Letras, 2012. p. 177-201.

. What's "new" in New Literacy Studies? Critical approaches to literacy in theory and practice. Current issues in comparative education, New York, v. 5, n. 2, p. 77-91, Spring 2003.

. Literacy and development: ethnographic perspectives on schooling and adult education. In: STREET, B. Literacy and Development. Ethnographic perspectives. London and New York: Routledge, 2001. p. 72-98.

. Social Literacies. Critical Approaches to Literacy in Development, Ethnography and Education. Harow: Pearson, 1998.

TFOUNI, L. V. T.; MONTE-SERRAT, D. M.; MARTHA, D. J. B. A abordagem histórica do letramento: ecos da memória na atualidade. SCRIPTA, Belo Horizonte, v. 17, n. 32, p. 23-48, $1^{\circ}$ sem. 2013.

TRIPP, D. Pesquisa-ação: uma introdução metodológica. Educação e Pesquisa, São Paulo, v. 31, n. 3, p. 443-466, set./dez. 2005.

ZANDWAIS, Ana. Demandas da pesquisa e diálogos entre teoria e prática. In: LEFFA, Vilson; ERNST, Aracy (Org.). Linguagens: metodologias de ensino e pesquisa. Pelotas: Educat, 2012. p.13-26.

Recebido em: Aprovado em: 